\title{
Dossiê... Cidades
}

\section{As máscaras da cidade}

\section{Lucrécia D'Allessio Ferrara}

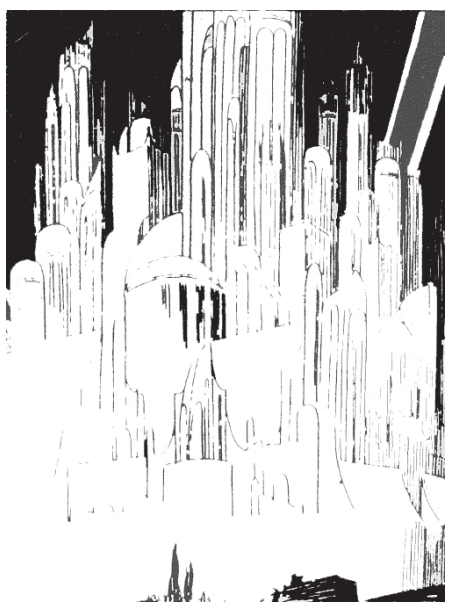

LUCRÉCIA D'ALLESSIO FERRARA ó professora da Faculdado de Arquitetura o Urbanismo (FAU) da USP o autora de Ver a cidade (Editora Nobel, 1988) ca, a linha de montagem, a especializaçăo da mäo-de-obra, o salário, o patrão, o operário, a manufatura, a tecnologia, a eletricidade, a eletrônica. Por sobre as causas e consequeéncias do fenômeno urbano, as imagens da cidade: ruas, avenidas, praças, galerias.

Além das explicaçóes sócio-económicas do urbano, estăo as imagens da cidade que assinalam uma robusta realizaçăo humana, uma forma distinta de civilização. Nessas imagens, estão as representaçס̄es, a linguagem urbana atravês da qual năo apreendemos as explicaçōes abstratas, mas aquelas constantes que atingem e modelam o nosso quotidiano. As imagens urbanas despertam a nossa percepção na medida em que marcam o cenário cultural da nossa rotina e a identificam como urbana: o movimento, os adensamentos humanos, os transportes, o barulho, o tráfego, a verticalizaçáo, a vida fervilhante; uma atmosfera que assinala um modo de vida e certo tipo de relações sociais.

As características culturais sedimentam a cidade enquanto império fervilhante de signos que cria uma linguagem e justifica uma ótica de estudos voltada para ela enquanto modo especffico de produzir informaçăo, ou seja, uma representaçăo, um modo de ser que substitui e concretiza o complexo económico e social responsável pelo fenômeno urbano.

Este trabalho parte do princípio de que é posslvel resgatar, nessa representaçăo, certa lógica histórica responsável por algumas categorias de manifestaçăo da linguagem urbana, isto é, as máscaras da cidade.

Enquanto representaçâo, a linguagem urbana năo esgota as características econômicas e sociais do fenómeno, mas procede a uma seleçăo nessas características e proporciona delas uma visăo parcial, e apenas possível.

Em outras palavras, a linguagem da cidade năo é uma propriedade do fenômeno urbano no sentido de distingui-lo e dâ-lo a conhecer, mas é operativa e funcional para o seu conhecimento: permite uma mediação no conhecimento do objeto que, por si só, não é auto-evidente.

Conhece-se o fenômeno urbano através da linguagem que o representa e constitui a mediaçăo necessária para a sua percepçăo: nảo pensamos o urbano senăo através dos seus signos. Entender a Iógica dessa representaçăo é condição necessária para produzir a teoria explicativa do urbano, ou seja, a fragilidade desse fenômeno na formulaçăo de sua auto-evidência e o caráter de mediaçẫo da imagem urbana para a compreensåo dele deixam claro a relaçāo que se estabelece entre fenómeno urbano como objeto de conhecimento através da imagem que o representa.

As transformaçōes econômicas e sociais deixam, na cidade, marcas ou sinais que contam uma história năo-verbal pontilhada de imagens, de máscaras que têm como significado o conjunto de valores, usos, hábitos, desejos e crenças que nutriram, através dos tempos, o quotidiano dos homens.

Este trabalho procurará resgatar estas marcas e tentará produzir uma Iógica da sua manilestação a fim de levantar um primeiro e provisório esboço de uma história da imagem urbana. Em 
outras palavras, a imagem polissensorial da cidade vem marcada por determinadas categorias que geram padrőes quase emblemáticos, assinalam momentos históricos e atraem a atençăo dos que se ocupam da cultura urbana. Combinando certa observação dos fatos a uma exigência de abstraçăo, é possível apreender aquelas categorias em vários momentos históricos e verificar a eficiência com que sintetizam uma representaçâo da cidade.

Dadas as dimensठes do assunto, é obvio que năo se pretende nenhum tipo de cobertura abrangente, mas, apenas, fixar algumas imagens urbanas no decorrer da historia, tendo em vista estabelecer as categorias de sua manifestaçăo.

Embora correndo o risco de uma indiscutível tendência à simplificaçăo, a tentativa desse esboço é sedutora pelo exercício de detida observação e esforço interpretativo.

\section{As máscaras da cidade}

Baudelaire publica seu Flores do mal em 1857 e cria uma grande personagem poética: a cidade, que é o tema de bom número de poemas. Porém, năo a cidade, mas uma cidade concretizada na sua alegoria: a multidăo como imagem flutuante, instável e fugaz atravês da qual o poeta via Paris e se transtormaria num dos mais renomados fisionomistas da imagem urbana.

A exemplo de Baudelaire, a história da imagem urbana é aquela que culmina com o relato sensivel das formas de ver a cidade; náo é descriçăo física, mas os instantâneos culturais que a focalizam como organismo vivo, mutante e ágil para agasalhar as relaçōes sociais que a caracterizam.

A história da imagem urbana colide ou se completa na história cultural da cidade que vem à luz sempre que focalizamos o espaço urbano na sua dimensāo social.

\subsection{A imagem urbana como indice social}

A cidade medieval deu origem a algumas imagens urbanas que, submetendo-se a várias translormaçס̄es, permanecem até os dias de hoje.

A cidade medieval foi um exercício de ousadia e inteligéncia de uma populaçăo rural que, capacitando-se profissionalmente, associava-se para encontrar um novo modo de ganhar a vida. Sua expressão econômica foram as guildas, porém suas características sociais e culturais passaram a se confundir com a propria cidade.

A vida nova, livre da tutela dos senhores leudais, a liberdade para produzir e superar suas dificuldades e, sobretudo, uma nova relaçăo social: a ajuda mútua. Para isso havia apenas uma lei: a competência no ofício e a associaçăo com seus iguais: a guilda de ofícios e seus artífices.

Tendo a produçăo e a habilidade como núcleo do quotidiano, a guilda era a demonstraçăo de uma vida comunitária que tinha seu estilo, suas crenças e religiảo marcados, até hoje, nos vitrais, rosáceas e murais dos seus monumentos, capelas e catedrais edificados com o vintém poupado na disciplina e ordem das corporaçōes.

Ao lado da competência no ofício, năo se dispensava a demonstraçăo da sua identidade signica, os indices, as marcas de um grupo ostentados nos trajes exibidos em praças públicas nas procissōes solenes, o corpo como suporte sígnico de uma sólida consciência da linguagem como mediação, como representação da estrutura social:

"No domingo depois da Assunçăo de Nossa Querida Senhora, eu vi a grande procissăo da Igreja de Nossa Senhora de Antuérpia, quando a cidade inteira, de todos os olícios e de todas as condiçōes, achava-se reunida, cada qual a usar as suas melhores roupas, conforme a sua posição.

E todas as ordens e corporaçōes ostentavam as suas insignias, pelas quais podiam ser reconhecidas.

- de Albrecht Duret $\phi 0$ princt. Yaulo XVI, colhida em $A$ cidado nia. suas origens, transtorma. serspectivas, Lewis Mumbro. b. Martins Fonlestediora da lade de Brashia, $2^{\prime}$ ed. bra982, D. 304.
Vı a procissáo passar ao longo da rua, o povo alinhado em fileiras muito próximas umas das outras. Estavam ali os Ourives, os Pintores, os Pedreiros, os Bordadores, os Escultores, os Marceneiros, os Carpinteiros, os Marinheiros, os Pescadores, os Alfaiates, os Sapateiros e enfim, trabalhadores de todas as espécies, e muitos artesáos e negociantes que trabalhavam para ganhar a vida"(1).

Essa corporação do trabalho organizava-se pela competência e disciplina, mas identificavase pelas insignias da sua profissão: a necessidade de mediar, pela linguagem, o reconhecimento do trabalho como objeto de classificaçāo social. 
Este signo indicial tinha o próprio corpo como suporte e a cidade como moldura. Corpo e cidade encontravam-se na procissáo para exibir, na praça pública ou na catedral, o instrumento signico do trabalho manual. Uma imagem urbana que apontava o homem e o seu trabalho como senhores de sua grande invençăo: a cidade.

Porém, o mesmo rigoroso apego à ordem e à disciplina deu origem a uma pesada estrutura hierárquica burguesa, que tinha, na riqueza, o elemento de destaque: estava preparado o terreno para uma outra imagem urbana medieval que se transformou e se prolongou até hoje: o carnaval.

\subsection{A imagem urbana como contraste}

No panorama cultural da estrutura econômico-social das guildas, nāo demorou que surgisse um espaço característico, o Paço Municipal, onde as faminias de destaque, os mais ricos artesãos e mercadores realizavam bailes, saraus, banquetes e casamentos com a devida pompa. O Paço Municipal era uma espécie de palácio coletivo, diz Lewis Mumford $^{(2)}$.

Eram as festas oficiais que consagravam uma ordem social apoiada no reconhecimento da estabilidade econôrnica e da perenidade da ordem social, onde todos tinham um lugar determinado: predominavam a hierarquia, os valores $e$, sobretudo, as leis e tabus religiosos, politicos e morais. Bakhntin e, mais recentemente, Burke são os grandes estudiosos dessa oficialidade festiva e do seu contraponto: o camaval ${ }^{[3}$ e 4)

Com a riqueza e o rompimento da ordem social corporativa das guildas, as camadas rica e pobre da população se delinearam de modo que apenas alguns eram admitidos nas festas oficiais do Paço Munıcipal; aos demais năo cabia, senão, o espaço e o tempo passageiros do carnaval, que deu origem a uma outra imagem urbana que brota na Idade Média e traz, até hoje, a sua grande persona. gem: a multidăo.

A mistura de tipos e atividades aglome-

rados dão uma outra função à praça pública que, durante alguns dias, abandona sua função comercial para abrigar um momento de quebra da rotina diária do trabalho e da vida comedida para desperdiçar, comer, beber e consumir todas as posses. Sobre esta ruptura do quotidiano, o carnaval na praça permite a exibição de uma das suas características básicas: a des-hierarquizaçăo. Rompe-se a distinção entre ricos e pobres, popular e erudito, particular e público, para criar um momento onde tudo ocorre ao ar livre, na praça ou na rua. Nessa primeira característica, cria-se uma imagem urbana franca e livre de restriçóes de qualquer norma ou etiqueta: sua característica sensorial ê a sonoridade que produz uma linguagem onde a comunicaçăo se laz aos brados e aos palavrð̋es. Nesse momento, a praça é o espaço livre e público que rompe a barreira da vida privada, das normas familiares, dos tabus morais e, sobretudo, da hierarquia social: uma festa, nâo somente popular, mas um espaço de todos e para todos.
Detalhe da obra "O retábulo de Mérode" (1425-1428), de Mestre de Flémalle

2 Lewis Mumlord, Op. ct., D. 298.

3 La cultura Dopulat en la Edad Modia y en el renacimiento - El conterto de François Rebelais, M. Bakhtin. Barce. lona, Barral Ed., 1971.

4 Cultura popular ma jodade moderna. Peter Burke. SAso Paulo. Edhtora Com panhin das Letras, 1989. 
Boulevard Bonne Nouvelle, Parts, 1900

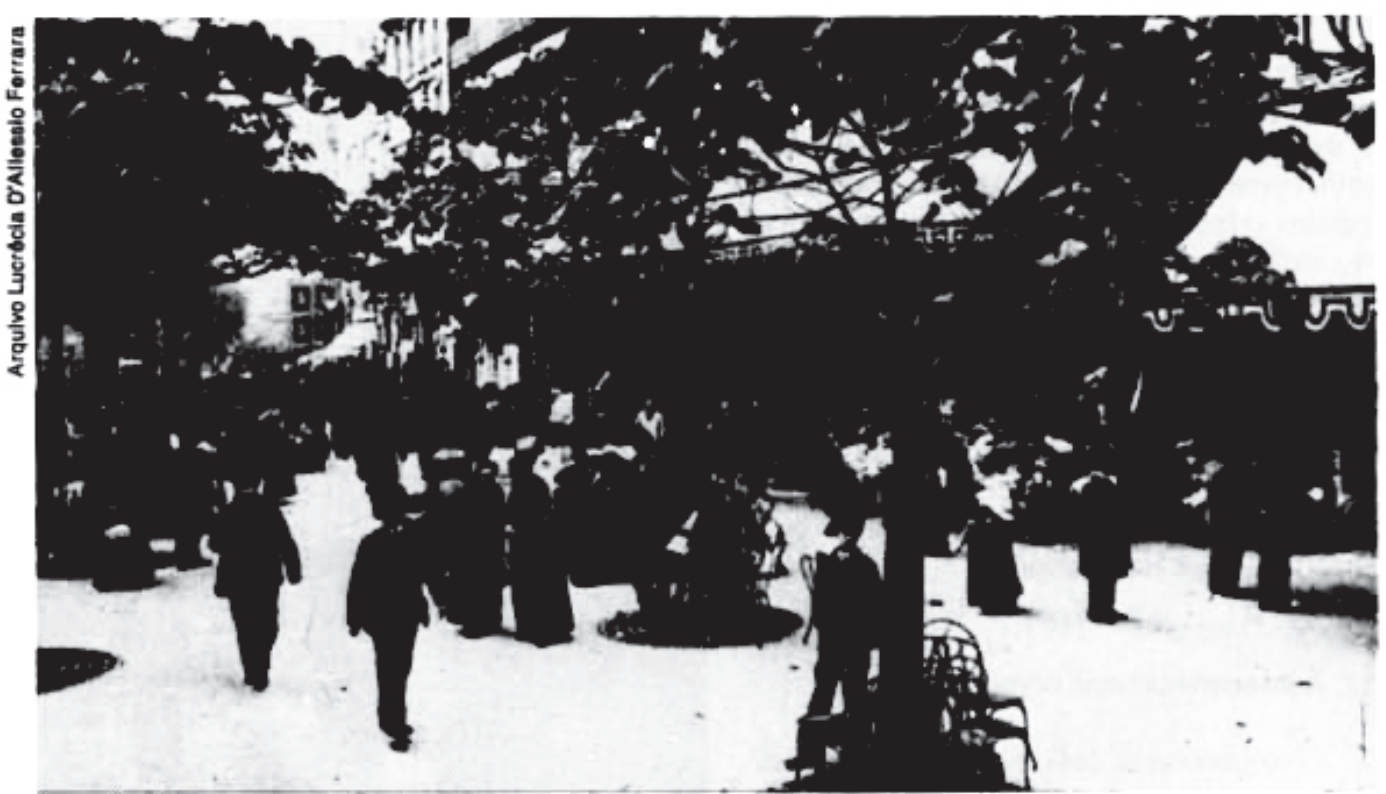

\subsection{A imagem urbana como inversāo}

Com o seu desenvolvimento, a imagem urbana carnavalesca do caos e da desordem se aprofunda e se torna mais complexa, ou seja, a quebra das convençốes cria, na praça pública, o espaço da inversăo, da exposiçăo da intimidade que passa a ser controlada pela exibiçăo. A praça jấ năo ê apenas o espaço público, mas o palco onde se dramatiza a inversão: o "mundo de cabeça para baixo"(5).

A praça é a cena onde todos săo atores e espectadores ao mesmo tempo; vive-se a ficçăo onde se exibem palhaços e mágicos mascarados num espetáculo de rua onde todos riem, um riso geral e universal. O espaço urbano transforma-se nesse local ambivalente: praça pública que abriga a festa da multidăo e cena dramática onde se invertem posiçőes sociais e se exibe, sob a forma de paródia, a intimidade familiar ou individual nos seus aspectos caricaturais; é a máscara, o individuo, os defeitos, os sexos travestidos.

A praça como cena dramática toma mais complexa a imagem do carnaval anti-hierárquico $e$ cria a imagem urbana da inversăo do privado que se torna público, do individual que se coletiviza, do defeito que se modifica em qualidade, da cultura popular que se oficializa e se impōe ao reconhecimento. Seu veículo sensorial é o gesto que, freqũentemente obsceno, se dramatiza e se multiplica na repetiçăo. Na praça carnavalesca, a multidăo colide com a inversâo e sua imagem ê espontânea e descontraida.

\subsection{A imagem urbana como poesia}

No século XIX, essa imagem urbana da multidão que se acotovela e colide transforma o uso coletivo no olhar que se cruza e se perde em inúmeros olhos aturdidos, surpresos e medrosos ao mesmo tempo.

O poeta dessa máscara da cidade é Baudelaire e o seu crítico, no início do século XX, é Walter Benjamin. Poeta e intelectual se unem para sentirem o impacto da cidade europeia, Paris ou Berlim, e o local dessa imagem urbana jâ năo é a praça pública, mas as longas ruas, as aveni das, os bulevares, as galerias, os becos da cidade que sofrem o impacto da metropolização.

No Flores do mal, Baudelaire insinua a figura urbana do olhar que com ele se cruza na multidâo, o olhar momentâneo, recluso e entediado da mulher que se exibe á medida que se oculta, que se nega à medida que se oferece: o bulevar é o local que permite e estimula esse olhar feito sexo e a multidåo é a espectadora, talvez desinteressada, dessa posse. 
Agile et noble, avec sa jambe de statue.

Moi, je buvais, crispé comme un extravagant,

Dans son oeil, ciel livide où germe l'ouragan,

La douceur qui fascine et le plaisir qui tue.

Un éclair... puis la nuit! - Fugitive beauté

Dont le regard m'a fait soudainement renaftre,

Ne te verrai-je plus que dans l'éternité?

Ailleurs, bien loin d'ici! trop tard! jamais peut-etre!

Car jignore où tu fuis, tu ne sais où je vais,

$O$ toi que jeusse aimée, $O$ toi qui le savais ${ }^{(0)}$

Esse anónimo habitante da metrópole é recolhido por Benjamin na figura do flâneur, estranha figura urbana que circula na Paris, capital do século XIX, como sua terra prometida ${ }^{(7)}$.

\subsection{A imagem urbana do ócio}

O flâneur é a personagem que agita a imagem do homem na multidăo que difere totalmente d'O homem da multidáo, conto de Edgar Poe, traduzido por Baudelaire. O fấneur năo é um autômato, mas, ao contrário, é um ocioso paradoxal que transforma a ociosidade em valor, porque a realiza produtivamente quando transforma as ruas, os pavilhőes, os grandes magazines, que atendem à necessidade coletiva da multidão, em instrumentos indiciais que relerencializam o labirinto emocional despertado pela cidade moderna.

Como um homem na multidâo, o flâneur desenvolve, metodologicamente, em torno de si um escudo que, por paradoxo, o situa na massa urbana sem permitir que nela se envolva, seu contacto urbano ế aquele do olhar, é a imagem da cidade sob a égide do olhar. Essa proteção metodológica taz do flâneur um habitante da cidade que rumina a imagem urbana na solidão do seu quarto quando revive, na memória, a lembrança de uma imagem, da visăo passageira resgatada, aprisionada no fluxo amorto dos quilômetros das ruas percorridas. É o homem na multidăo que luta diante da linha evanescente que ainda persiste entre o espaço público e a reserva da intimidade e, por isso, ainda pode surpreender-se, chocar-se ante a imagem urbana. Năo está condicionado pelo hábito que automatiza a percepçăo e impede a apropriaçăo da cidade pelo cidadăo, essa doença que, perplexos, assistimos corroer a imagem da metrópole moderna.

A Paris do século XIX, que encanta Benjamin através de Baudelaire, ê a cidade da experiência urbana assumida $e$, por isso, torna-se a cidade lírica que faz do poeta um fisionomista da imagem urbana.

\subsection{A Imagem urbana como reminiscência}

A prudência metodológica, para não perder-se na multidáo e resgatar a imagem da cidade que Benjamin capta no ocio baudelairiano, acaba por atingi-lo em outra vertente, no fascínio com que se entrega à sedução urbana em inúmeras passagens da sua obra mas, sobretudo, em três textos básicos: "Rua de mão única", "Infância em Berlim" e "Imagens do pensamento"(B).

A reminiscência de Benjamin, em lugar de ser de măo única, está, na verdade, na contramão, porque busca reavivar não a lembrança do que foi perdido, mas acender a curiosidade para saber por que foi perdido. Uma outra e estranha maneira de surpreender a história da imagem urbana: uma história onde o coletivo e o individual se cruzam numa avalanche alegórica, até năo sabermos se a imagem é a da cidade ou a do critico à procura de um espaço perdido.

Desse cruzamento surge um método, ao mesmo tempo afetivo e cognitivo:

"Aquelas (rotas) que para os outros são desvios, săo, para mim, os dados que definem a minha rota. Eu baseio os meus cálculos nos diferenciais do tempo que para os outros perturbam as 'grandes linhas' da pesquisa.

Este trabalho deve desenvolver ao máximo grau a arte de citar sem aspas. A sua teoria está intimamente relacionada com aquela da montagem.

Nada tenho para dizer. Apenas para mostrar"(9).

6 - $A$ une passante", Charles Baudelaire. in Les fleurs du mal (Tableaux partsiens), Oouvres compldios. Paris, Gatllimard, 1954.

7 Parigi capitale del XIX socolo, Walter Benjamin. Turim, Einaudl, 1986 , Pp. 5 - sogs. o pp. 543 o segs.

8 Tus de mao anica", Walter Benjamin, in Obras escolhidas II. SAo Paulo. Brasilienso, 1987.

- Teorla della conoscenza - del pro groseo", Wahter Benjamin, Op. clt., pp. 591 e segs. 
As reflexōes do adulto montadas sobre as reminiscências infantis desenvolvem uma sensibilidade inteligente que garante a passagem da subjetividade impressionista à construçăo de um lugar no espaço urbano: a rua de mão única, a rua Asja Lacis nāo é a justaposição de casas e lojas, mas um lugar onde ecoam as vozes do passado acordadas pelas lembranças e, alegoricamente, representadas por detalhes e fragmentos:

"Saber orientar-se numa cidade năo significa muito. No entanto, perder-se numa cidade, como alguém se perde numa floresta, requer instruçăo. Nesse caso, o nome das ruas deve soar para aquele que se perde como o estalar do graveto seco ao ser pisado, e as vielas do centro da cidade devem refletir as horas do dia tão nitidamente quanto um desfiladeiro. Essa arte aprendi tardiamente; ela tornou real o sonho cujos labirintos nos mata-borrőes de meus cadernos foram os primeiros vestígios. Năo, năo os primeiros, pois houve antes um labirinto que sobreviveu a eles. $\mathrm{O}$ caminho a esse labirinto, onde nâo faltava sua Ariadne, passava por sobre a ponte Bendler, cujo arco suave se tornou minha primeira escarpa"(10).

Pelo método da montagem de reminiscências, a cidade é percorrida como um livro tridimensional em prontidăo de linguagem onde o acúmulo de objetos, estátuas, passagens, becos sem saida, publicidades, escritas verticais săo semblantes realistas de um macrocosmo social e ensinam pelo método mais direto, aquele da experiência. Apenas esse método, que trabalha por dentro e através das sensaçóes, permitiria que o intelectual criasse uma imagem tão insólita de Paris, outra cidade que o atrai e fascina como cidade no espelho:

"Pois sobre os desnudos quais do Sena há séculos se deitou a hera de folhas eruditas: Paris é um grande salăo de biblioteca atravessado pelo Sena"(11).

As reminiscências, o método da montagem sem aspas e a prontidăo da linguagem fazem da imagem urbana de Benjamin um recorte de quadros e detalhes selecionados pela memória e localizados alegoricamente; em consequeência, temos uma imagem descentrada fisicamente, porém concentrada de emoçōes. Nāo se pode saber onde está a realidade, se no detalhe da cidade gerado por uma lembrança, ou na retórica com que se aprisiona uma emoçăo. Na realidade, não temos propriamente, para Benjamin, uma imagem urbana, mas a atenta observaçăo de quem procura descobrir o processo de percepçăo responsável pela geração daquela imagem descontinua, produzida aos saltos. Uma outra forma de escrever a história da imagem urbana: dar aos locais a fisionomia capaz de torná-los significativos e legiveis.

\subsection{A imagem urbana como objeto}

Conforme muitos diagnósticos conhecidos, a segunda metade do século XX sofre o impacto de uma cultura e consumo de massa possibilitados pelo acesso à informaçăo, via televisăo, e ao produto, via um processo crescente e diversificado do mundo industrial e da superproduçăo. Esta realidade traz conseqüências em todos os prismas da sociedade contemporânea e a imagem da cidade apresenta os sinais inelutáveis desse desafio social.

A competitividade do capitalismo industrial projetando-se sobre a imagem cultural urbana descaracteriza a cidade enquanto espaço público, na medida em que lhe tira todo caráter próprio e declarado de expressăo social através do espaço.

Como vimos, da cidade medieval até aquela do século XIX, encontramos definitivas manifestaçōes culturais que, ao socializarem o espaço, conferem-lhe as imagens que o apontam como o lugar onde o indivíduo, ampliando-se no povo, na multidão, expressa, publicamente, seus anseios, valores e crenças. A imagem da cidade dos nossos dias esvazia-se das manifestaçōes culturais que tinham a multidâo como personagem e o individuo podia expressar, em públicó, suas emoçōes urbanas. A imagem urbana esvaziou-se, na medida em que desaparece a sua grande protagonista: a multidăo. Esvaziou-se a imagem e, em conseqūência, alterou-se a linguagem e o significado do espaço urbano.

A praça, a avenida, a multidāo, enquanto expressర̌es públicas da cidade, foram substituidas pelas versōes urbanas intimas, demarca-se claramente o espaço individual separando-o do coletivo e reivindica-se a demonstração sígnica dessa divisăo em nome da propriedade, da segurança, da tranquilidade íntima e da livre expressão.

Nessa nova imagem urbana colidem o público e o privado, prevalecendo o segundo sobre o

10 "Intancia om Berlim por volta de $1900^{*}$ Walter Benjamin, in Obras es. colhidas II, p. 73.

11 "Imagens do pensamento" Walter Benjamin, in Obras escollhidas $\|, \mathrm{p}$. 195. primeiro na medida em que, agora, os espaços coletivos urbanos - praças, avenidas, ruas, galerias, lojas, pavilhőes - cedem lugar à habitaçăo como espaço urbano da intimidade, espaço vedado, seguramente protegido por portőes, grades, muros, múltiplos signos de vedaçăo, o mundo da solidăo, a casa como lugar onde nos escondemos. 


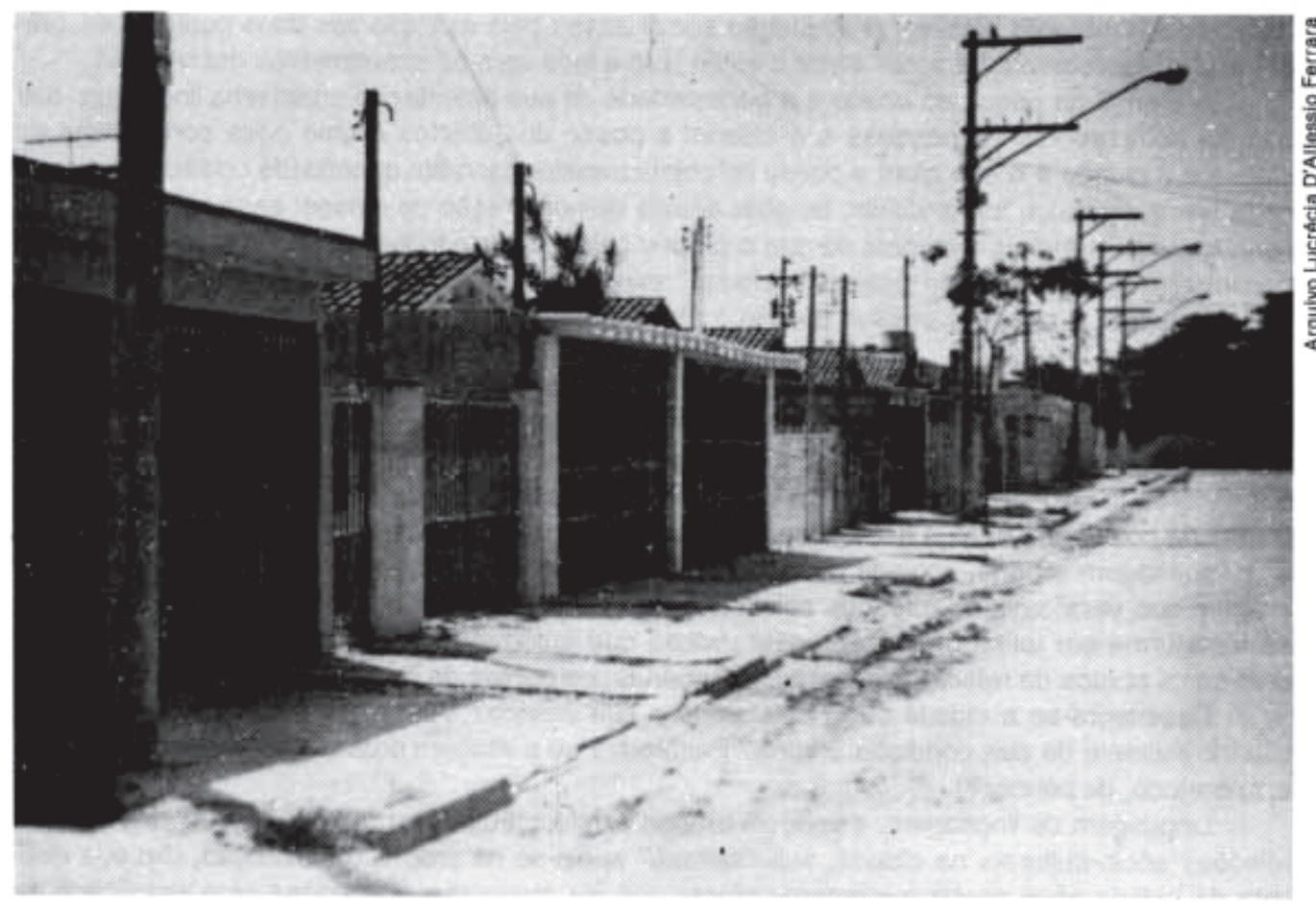

Truncada definitivamente a imagem urbana da sociabilidade, os signos, agora, sāo outros.

Subtraindo-se à ansiedade e agressăo que the causa qualquer contacto público, o urbanita de hoje refugia-se em esquemas de proteção: a condução própria, os fins de semana usufruídos no refúgio do campo, os apartamentos longe do ângulo de visão da rua, os condomínios fechados, a propriedade privada, índices de segurança definidos pela familia e pelos amigos intimos.

Voltada para o interior da habitaçăo, a imagem urbana nutre-se dos signos que a distinguem e diversificam: os objetos, motivo de conquista de uma luta diária, porque entendidos como prolongamento, extensão das qualidades dos proprietários ou, mais ainda, a posse do objeto como fator de nova e otimista compreensão do universo.

A crença no objeto ultrapassa seu caráter racional funcionalista e valoriza-se a representação, a linguagem.

Marx chamou essa atração de "fetichismo das mercadorias", uma espécie de religiăo ou de narcótico, e foi um, dentre muitos, que se impressionou com o fato de se revestir coisas materiais com atributos sociais e afetivos, com sua fácil manifestaçăo em termos de massa e, sobretudo, com o seu resultado, uma inevitável homogeneizaçăo da aparência.

Realmente, possuir os mesmos objetos passou a significar ser igual, atuar igual, aparecer igual e, sobretudo, pensar igual: condiçẫo de defesa pessoal nas relaçōes sociais urbanas.

Dai decorrem duas consequeências básicas.

Em primeiro lugar, a presença dos mesmos objetos nâo é só responsável por aquela pasteurização, mas a posse dos mesmos objetos traz a distinçăo e a segurança sociais. Essa recompensa passa a ser procurada compulsivamente e assume o caráter icônico da acumulaçăo kitsch: do amontoado de objetos de porcelana ou vidro até o eletroeletrônico de vários modelos, procedências e funçōes auratizados à feição de obra de arte e, sobretudo, expostos nas indefectlveis estantes de madeira barata e desenho duvidoso. $O$ fetiche da mercadoria passa, antes de tudo, pela posse e exibição dela.

Grandes perguntas decorrem dessa representaçăo urbana: qual a razāo desse caráter antropologico dos objetos? O que teria levado o individuo a resgatar sua imagem pública pela representaçăo das suas posses?

As respostas a estas duas questőes nos levam à segunda característica anunciada.

A imagem urbana desse final de século, dominada pela intimidade em detrimento da exposição pública, é uma ficção. Na realidade, ainda é a aceitação pública que domina a vida privada, é o reconhecimento de todos que determina a segurança individual. Daí a aparência, a fachada das habitaçōes ou dos edifícios serem altamente reveladoras: as grades altas e pontiagudas lá năo estão como segurança e proteção, mas são signos do poder econômico e, sobretudo, da propriedade, demarcam e exibem a divisăo entre o público e o privado para que se promova o ambicio-
Foto de um bairro de São Miguel Paulista, Sáo Paulo, 1989 
nado reconhecimento coletivo. A aceitação social passa pela exibição dos bens particulares, grades e portōes vedam para poder exibir e eståo lado a lado com os acabamentos decorativos.

A crença na posse do objeto e a necessidade de sua ostentação criam uma linguagem que permite compreender as pessoas e a cidade: a posse dos objetos é uma nova consciência de classe e a cidade é o seu altar: a posse do objeto transformado em quantidade codifica o lugar de cada um e digitaliza, torna visível, tangivel aquela demonstração de classe; essa representação, essa linguagem é mais funcional do que o próprio objeto e varre todas as classes, pois é possivel encontrar o mesmo "fetiche das mercadorias" exposto, das mansōes de elite às habitaçठes populares: agora, a classe é possuir ou náo o objeto em grande quantidade e modelos diferentes e atuais.

A posse do objeto tudo unifica e torna igual: espaços, habitaçóes, pessoas, personalidades e, paradoxalmente, a contraposiçăo entre a vida privada e pública, mais que separaçấo, é a os. tentaçáo dos opostos como marca de uma nova imagem urbana que se elabora pela aceitaçáo dos valores individuais, exibidos para a consideraçăo pública. $E$ tudo ocorre naturalmente, essa cultura da posse do objeto já năo causa espanto e o que parece estranho é năo aderir a ela.

A imagem urbana, apoiada nos icones da vida privada, acaba por desintegrar aquela outra imagem que valorizava os espaços coletivos: a rua, a praça, o largo, a avenida; 0 uso da cidade se transforma em rotina organizada pela pressa que automatiza e unifica todos os lugares; perdem-se os pontos de referência, as marcas urbanas, os pontos de encontro.

Desintegra-se a cidade ou constatamos a sua velhice? Desaparece o cidadăo ou surge 0 usuário ausente da sua condição urbana? Pasteuriza-se a imagem urbana que nos impede de ver e, sobretudo, de pensar?

Linguagem de linguagem, a imagem urbana é mediação para compreender o significado das relaçōes sócio-culturais na cidade, sua "sintaxe" apoia-se na própria urbanizaçăo, isto ê, a imagem da cidade atual revela o momento crucial que ela atravessa: transforma-se o significado da cidade ou seria ela descartável como os objetos e sua imagem passaria por sucessiva e cada vez mais rápida substituição? Ou, ao contrário, essa imagem urbana apontaria, apenas, para uma radical mudança? Da cidade do século XIX e início deste a sofrer os primeiros impactos da metropolizaçăo, como as transformaçōes introduzidas em Paris pelo prefeito Hausmam, à cidade de hoje, asfixiada pelo gigantismo da megalópole, encontramos uma imagem urbana cada vez mais vulnerável e intrigante, na medida em que se descaracteriza como espaço de uso coletivo, para tornarse anónima, mas necessária. Essa imagem urbana năo é natural, mas esconde um desafio que exige resposta, criativa.

\section{BIBLIOGRAFIA}

BAJTIN, Mijail, La cultura popular en la Edad Media y en el renacimiento. Barcelona, Barral, 1971. BAUDELAIRE, Charles, Oeuvres complètes. Paris, Gallimard, 1954.

BAUDRILLARD, Jean, A sombra das maiorias silenciosas. Săo Paulo, Brasiliense, 1985. BENJAMIN, Walter, Parigi capitale del XIX secolo. Turim, Einaudi, 1986.

- Obras escolhidas II - Rua de mão única. Såo Paulo, Brasiliense, 1987.

- Documentos de cultura documentos de barbárie. Săo Paulo, Cultrix/Edusp, 1986.

BURKE, Peter, Cultura popular na idade modema. Săo Paulo, Companhia das Letras, 1989.

CORBIN, Alain, Saberes e odores. Săo Paulo, Companhia das Letras, 1987.

DUBY, Georges, O tempo das catedrais. Lisboa, Ed. Estampa, 1988.

GINZBBURG, Cario, Mitos emblemas sinais. Săo Paulo, Companhia das Letras, 1989.

HEERS, Jacques, Festas de loucos e carnavais. Lisboa, Dom Quixote, 1987.

HUBERMAN, Leo. História da riqueza do homem. Rio de Janeiro, Guanabara, 1986.

MUMFORD, Lewis, A cidade na história, suas origens, transformaçóes e perspectivas. Săo Paulo, Martins Fontes/Ed. da Universidade de Braslia, 1982.

PEIRCE, Charles Sanders, Collected papers. Cambridge, Harvard Press, 1974, 4 vols.

SANTOS, Milton, O espaço do cidadao. Săo Paulo, Nobel, 1987.

SENNETT, Richard, O declínio do homem público. Săo Paulo, Companhia das Letras, 1989.

WILLIAMS, Raymond, O campo e a cidade. São Paulo, Companhia das Letras, 1989. 